\title{
A magnetic resonance (MR) compatible selective brain temperature manipulation system for preclinical study
}

This article was published in the following Dove Press journal:

Medical Devices: Evidence and Research

2 March 2012

Number of times this article has been viewed

\author{
Qingwei Liu' \\ Yu Cai' \\ Weili Lin² \\ Gregory H Turner ${ }^{3}$ \\ Hongyu $\mathrm{An}^{2}$
}

'Biomedical Research Imaging Center, University of North Carolina at Chapel Hill, NC, USA; ${ }^{2}$ Department of Radiology and Biomedical Research Imaging Center, University of North

Carolina at Chapel Hill, NC, USA;

${ }^{3}$ Neuroimaging Research, Barrow

Neurological Institute, Phoenix, AZ, USA

Correspondence: Hongyu An

Department of Radiology and Biomedical Research Imaging Center, CB\#75I3,

University of North Carolina at

Chapel Hill, Chapel Hill, NC 27599, USA

Tel + I 9198438256

Fax + I 9198434456

Email hongyuan@med.unc.edu

Correspondence: Qingwei Liu St Joseph's Hospital and Medical Center, Keller Center for Imaging Innovation, 350 West Thomas Road, Phoenix,

AZ 85013 , USA

Tel +l 6024062643

Fax + I 602406339 |

Email qingwei.Liu@chw.edu
Abstract: There is overwhelming evidence that hypothermia can improve the outcome of an ischemic stroke. However, the most widely used systemic cooling method could lead to multiple side effects, while the incompatibility with magnetic resonance imaging of the present selective cooling methods highly limit their application in preclinical studies. In this study, we developed a magnetic resonance compatible selective brain temperature manipulation system for small animals, which can regulate brain temperature quickly and accurately for a desired period of time, while maintaining the normal body physiological conditions. This device was utilized to examine the relationship between T1 relaxation, cerebral blood flow, and temperature in brain tissue during magnetic resonance imaging of ischemic stroke. The results showed that this device can be an efficient brain temperature manipulation tool for preclinical studies needing local hypothermic or hyperthermic conditions.

Keywords: selective brain cooling, hyperthermia, hypothermia, brain temperature mapping, ischemic stroke

\section{Introduction}

Hypothermia has been shown to improve the outcome of acute cerebral ischemia. Its potential has been underlined by randomized clinical trials in patients with global cerebral ischemia after cardiac arrest ${ }^{1}$ and in infants with moderate or severe hypoxicischemic encephalopathy, ${ }^{2}$ in which cooling reduced mortality and disability. In addition, several prospective observational studies have demonstrated that higher body temperatures are associated with poor outcome after stroke. ${ }^{3,4}$

The mechanism of the effect of hypothermia has been widely studied. Preclinical studies have suggested that hypothermia affects a wide range of cell death mechanisms including reduction of cerebral oxygenation and metabolism, ${ }^{5-9}$ alteration in oxygen free radicals release, ${ }^{10-14}$ decreases in the release of excitotoxic neurotransmitters,,${ }^{15-17}$ reduction or delay in apoptosis, ${ }^{18-20}$ and preservation of the blood-brain barrier. ${ }^{21-24}$ However, there is no final conclusion yet on the exact mechanism behind beneficial hypothermia.

It has been recognized that the protective effect of hypothermia is closely related to the treatment window, duration and degree of the hypothermia. ${ }^{25}$ Studies show that the earlier the application of the hypothermia, the better protective effect achieved. It has also been suggested that the brain is highly sensitive to temperature alterations. ${ }^{26-28}$ A small decrease in brain temperature by only a few degrees leads to significant neuroprotective effects in ischemic stroke, while a slightly increased brain temperature exacerbates brain injury. ${ }^{18,21,26,28-40}$ Thus, for the stroke studies involving applications 
of hypothermia, an accurate, fast, and consistent control of brain temperature for a desired period of time is of crucial importance.

At present, systemic cooling is the most widely used method to induce and maintain mild hypothermia, but the decreasing of body temperature can lead to multiple side effects, such as shivering, pneumonia, arterial hypotension, thrombocytopenia, bradycardia, infection, and myocardial infarctions. ${ }^{41-45}$ Instead, selective brain cooling (SBC) methods can induce hypothermia in the brain, while maintaining normothermic body temperature, which could suppress the side effects. Although several selective cooling devices have been developed, ${ }^{46-49}$ their incompatibility with magnetic resonance (MR) imaging highly limited their applications in preclinical studies.

In this study, we designed a selective brain temperature manipulation system that was able to accurately and consistently regulate the brain temperature of rats. The target temperature can be reached within minutes and maintained for a desired period of time, while keeping the body temperature within normal range. In addition, the system is MR compatible, which highly expands its application in preclinical studies. Utilizing this device, we studied the relationship between the MR parameter T1 (spin-lattice relaxation time), cerebral perfusion, and brain temperature during MR imaging of ischemic stroke.

\section{Methods}

\section{Instrument design}

As shown in Figure 1, the MR compatible temperature manipulation device was composed of a brain cooling set, a body heating set, and temperature sensor set, which were placed inside the scanner room, a temperature measurement module

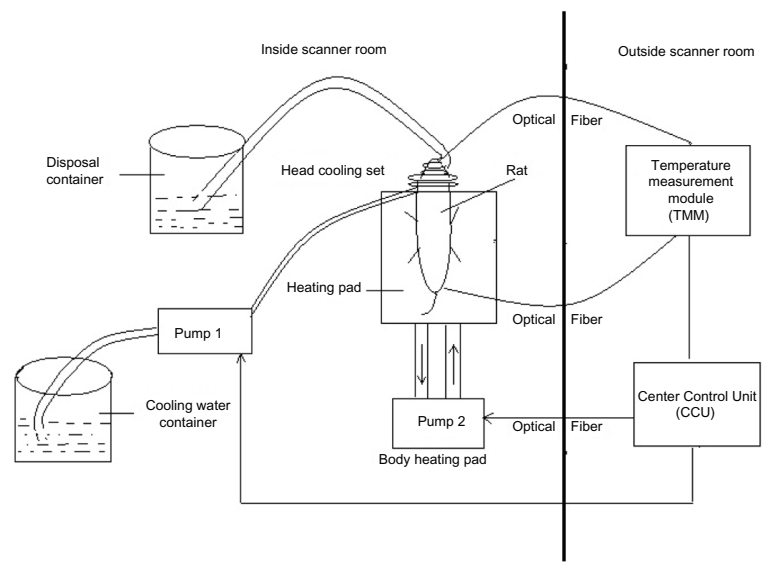

Figure I The diagram of the local temperature manipulation system. and a center control unit (CCU), which were placed outside the scanner room. For MR compatible consideration, in order to avoid radio frequency noise and allow for MR compatibility, optical fibers were used to transfer the signals between the components inside and outside the scanner room.

The brain cooling set was used to control the brain temperature. It was composed of the brain cooling coil, silicone tubing, peristaltic pump (SCI400D/U1; Watson Marlow Inc, Wilmington, MA), cooling water container, and disposal container. The cooling coil was built with a PE 50 polyethylene tube (BD Intramedic ${ }^{\mathrm{TM}}$, Franklin Lakes, NJ), which was designed to fit the head of a rat. The cooling water was pushed by the peristaltic pump, flowed through the cooling coil, and went into the disposal container. The flow of cooling water was controlled by adjusting the speed of the pump, which was regulated by an analog voltage signal sent by the CCU.

The body heating set was used to maintain body temperature within the normal physiological range. It was composed of a body heating pad, heating pump (Gaymar, Shakopee, $\mathrm{MN}$ ), and heating pump control module. The control module was the interface between the pump and CCU, which received the optical signal from the CCU to control the on/off of the heating pump.

The temperature sensor set (Luxtron Inc, Santa Clara, CA) was composed of two optical temperature sensors, one for the brain temperature and another for the rectal temperature, with the tip size of $0.5 \mathrm{~mm}$. The temperature was derived by the wavelength difference between the emission and reflection lights, which went through the optical fiber between the sensor tip and the temperature measurement module. The temperature measurement module converted the temperature to an analog voltage signal and then transferred it to the CCU.

The CCU was the processing center for the whole system. It was composed of a BASIC Stamp microcontroller (Parallax, Rocklin, CA), analog-to-digital converter (A/D) and digital-to-analog converter (D/A) interface unit, and an optical communication interface circuit. The BASIC Stamp microcontroller, with a small, specialized BASIC interpreter built into the read only memory. It provided twelve digital output ports and input ports, which were used to communicate with other digital devices. A self-developed program was stored in the read only memory to control the processing of the whole system. The A/D and D/A interface circuits were realized by TLV5616C (Texas Instruments Inc, Dallas, TX) and TLC2543 (Texas Instruments Inc) chips. TLV5616 was a 12-bit voltage output digital-to-analog converter with a flexible 4-wire serial interface, while TLC2543 was a 12-bit switchedcapacitor, successive-approximation, analog-to-digital 


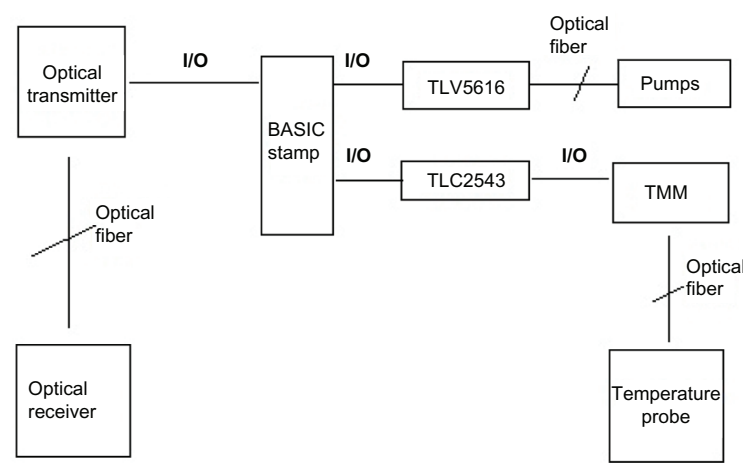

Figure 2 Center control unit (CCU) and peripheral circuit. Abbreviation: TMM, temperature measurement module.

converter. The optical communication interface circuit was composed of an optical-electric converter, comparator, inverter, amplifier and driver, light-emitting diode light, and optical fiber and other components. It provided the conversion between electrical signal and optical signal, and supported the communication between the units inside and outside the scanner room for MR compatibility. The electrical diagrams of the CCU and peripheral circuit, optical communication circuits (transmitter and receiver), and pump control circuit are shown in Figures 2, 3, and 4.

Hypothermia and hyperthermia were induced in the brain by using either cold or warm water respectively. Two fiber optic thermo-probes were used to measure the brain temperature and body temperature. The brain temperature measured with a fiber optic thermo-probe was transferred to the CCU, which then adjusted the flow rate of the peristaltic pump accordingly. The core body temperature was used as the feedback signal to maintain the desired body temperature at $37.0^{\circ} \mathrm{C} \pm 0.5^{\circ} \mathrm{C}$ by switching the heating pump on or off.

\section{Animal procedures}

All animal protocols were approved by the Institutional Animal Care and Use Committee at the University of North Carolina at Chapel Hill. A total of 26 Long-Evans rats
( $\mathrm{n}=26 ; 300 \pm 25 \mathrm{~g}$; Charles River Inc, Wilmington, MA) were used over the course of this study. Among them, nine rats were used to verify temperature manipulation, five rats were used to test the relation between $\mathrm{T} 1$ relaxation and temperature, seven rats were used to study the relations between perfusion and temperature in the brain under ischemic stroke, and five rats were used to study the temperature difference between temporal muscle and brain. Anesthesia of the animal was induced (3\%) and maintained (1.5\%) using mechanical ventilation with isoflurane. Animal body temperature was maintained within $37.0^{\circ} \mathrm{C} \pm 0.5^{\circ} \mathrm{C}$ by a servo-controlled water heating pad during surgery. Each rat was implanted with two fiber optic thermo-probes. A small hole $(\varphi=1.0 \mathrm{~mm})$ was opened in the scalp, $2 \mathrm{~mm}$ right of the midline and $2 \mathrm{~mm}$ under the bregma on the right side of the head. One probe was inserted at a right angle through the hole, with a depth of $4.0 \mathrm{~mm}$. Another probe was inserted into the rectum, with a depth of $4.0 \mathrm{~cm}$, to measure the core body temperature. The mean arterial blood pressure (MABP) and heart beat rate (HBR) were recorded through a femoral artery catheter with a blood pressure (BP) analyzer (Micro-Med, Louisville, KY).

\section{Experiment to verify temperature manipulation}

A total of nine Long-Evans rats $(\mathrm{n}=9 ; 300 \pm 25 \mathrm{~g})$ were employed to determine the effectiveness of brain temperature manipulation using the developed system. Five different brain temperature manipulations, hyperthermia $\left(39^{\circ} \mathrm{C}\right)$, normothermia $\left(37^{\circ} \mathrm{C}\right)$, hypothermia $\left(35^{\circ} \mathrm{C}, 32^{\circ} \mathrm{C}\right.$, and $\left.29^{\circ} \mathrm{C}\right)$ and a three-phase hypothermia $\left(29^{\circ} \mathrm{C}, 32^{\circ} \mathrm{C}\right.$, and $\left.35^{\circ} \mathrm{C}\right)$ were conducted. For the different target temperatures, the temperature of the flowing water was preset to $40^{\circ} \mathrm{C}, 25^{\circ} \mathrm{C}$, and $15^{\circ} \mathrm{C}$ respectively. For the three-phase hypothermic condition, the brain temperature was first cooled down to $29^{\circ} \mathrm{C}$, maintained for 30 minutes, rewarmed to $32^{\circ} \mathrm{C}$, maintained for another 30 minutes, rewarmed to $35^{\circ} \mathrm{C}$ and maintained for 30 minutes.
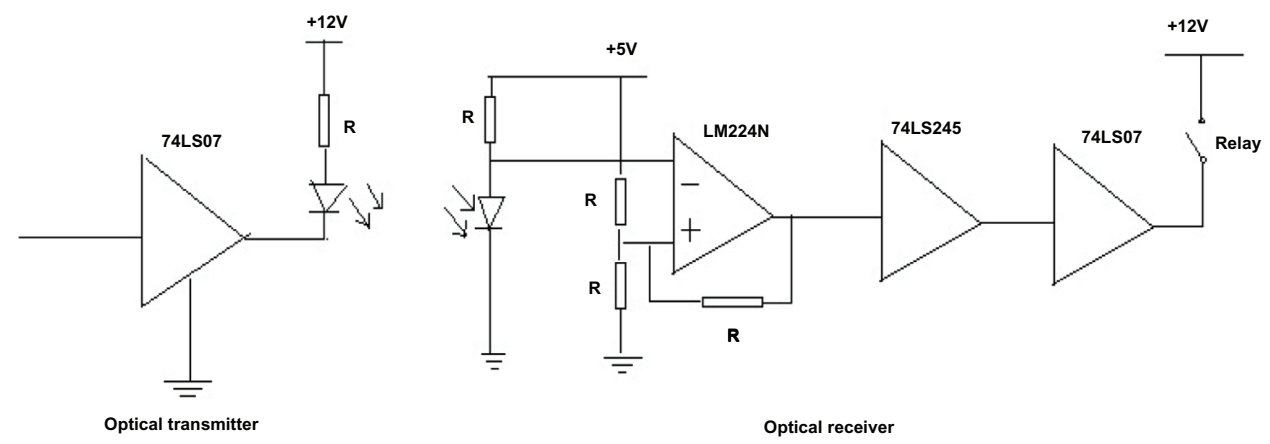

Figure 3 Optical transmitter and receiver circuit. 


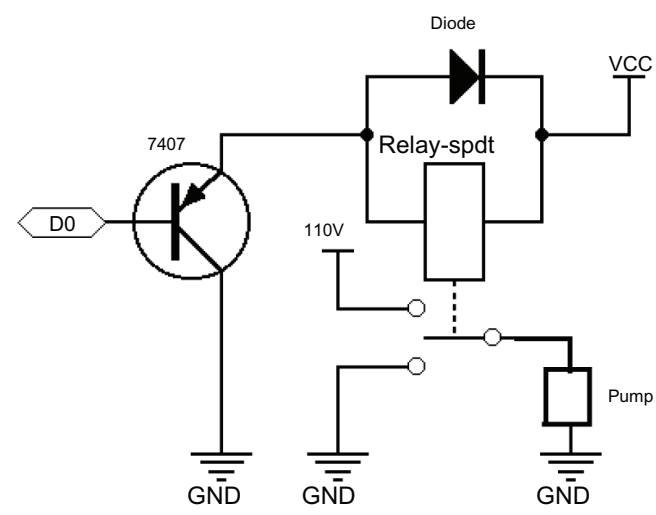

Figure 4 Pump control circuit. Abbreviations: GND, ground; VCC, positive supply voltage (+I2V).

\section{MRI experiments}

\section{Relation between $\mathrm{TI}$ relaxation and temperature}

All MR images were acquired on a Siemens 3T Allegra (Siemens Medical Systems, Erlangen, Germany) with a $4.3 \mathrm{~cm}$ custom birdcage volume coil (Nova Medical, Waltham, MA). The system was manually shimmed to minimize background magnetic field variation.

A total of five Long-Evans rats ( $\mathrm{n}=5 ; 300 \pm 25 \mathrm{~g}$ ) were utilized to study the relation between $\mathrm{T} 1$ relaxation and temperature. For each animal, the brain temperature was manipulated from $37^{\circ} \mathrm{C}$ to $35^{\circ} \mathrm{C}, 32^{\circ} \mathrm{C}$ and $29^{\circ} \mathrm{C}$ sequentially with the developed system. The temperature was maintained at each hypothermia level for 20 minutes, while a Look-Locker sequence ${ }^{50}$ was utilized to acquire the recovery of the signal and then derive the T1 map. A thermo-probe inserted into the brain, as mentioned above, provided a direct temperature measurement of the brain temperature. The $\mathrm{T} 1$ value at normal brain temperature $\left(37^{\circ} \mathrm{C}\right)$ was utilized as the reference and the relative change of $\mathrm{T} 1$ versus the change of temperature was studied. Since the insertion of a thermo-probe may cause brain tissue damage and result in potential signal variation in $\mathrm{T} 1$ maps, a region of interest (ROI) placed at a

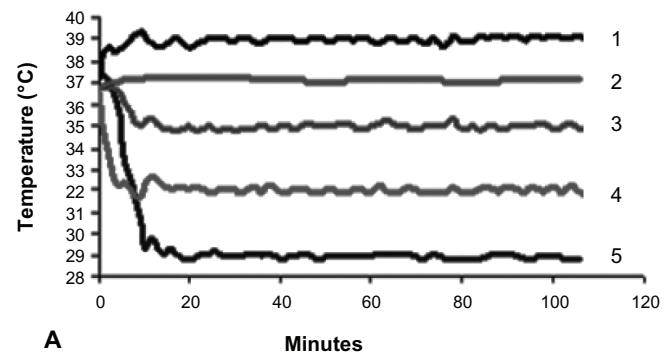

mirror location in the contralateral hemisphere was used for the estimation of T1, assuming that the temperature in the symmetric regions of the other hemisphere is very similar. The linear correlation between the mean $\mathrm{T} 1$ from the ROI and thermo-probe measurement was derived.

\section{Relations between perfusion and temperature}

Five Long-Evans rats $(\mathrm{n}=5 ; 300 \pm 25 \mathrm{~g})$ were utilized to study the relationship between cerebral blood flow (CBF) and temperature in different regions under ischemic stroke. The cerebral ischemia was induced using the intraluminal suture middle cerebral artery occlusion model ${ }^{51}$ under the normothermic condition. Briefly, all animals were anesthetized with isoflurane as described previously and a 4-0 nylon monofilament with a heat-blunted tip was inserted through an arteriotomy of the common carotid artery. The suture was advanced 20-22 $\mathrm{mm}$ into the internal carotid artery to induce middle cerebral artery occlusion. For comparison, a sham operated group ( $\mathrm{n}=2 ; 300 \pm 25 \mathrm{~g})$ was used, with a similar experimental procedure but without occluding the middle cerebral artery. Three different hypothermic conditions, including $35^{\circ} \mathrm{C}, 33^{\circ} \mathrm{C}$, and $31^{\circ} \mathrm{C}$ were achieved sequentially.

In order to determine how hypothermia affects cerebral perfusion under different ischemic severity, apparent diffusion coefficient (ADC), CBF, and T1 maps were acquired at each hypothermic condition. More specifically, T1 maps were acquired with a Look-Locker method, ${ }^{50} \mathrm{CBF}$ maps with a continuous arterial spin labeling ${ }^{52,53}$ method, and ADC maps with a three direction diffusion weighted image method. All the data was processed using house made programs, with the procedure the same as in the references. ${ }^{52,53}$

For the ischemic rats, three ROIs were examined: core, mismatched, and contra. The core region was defined as the region with ADC abnormalities ( $<$ mean-3 $*$ SD [standard deviation] of the contralateral hemisphere). The mismatched region was defined as the hypoperfused $\mathrm{CBF}(<$ mean- $3 * \mathrm{SD}$

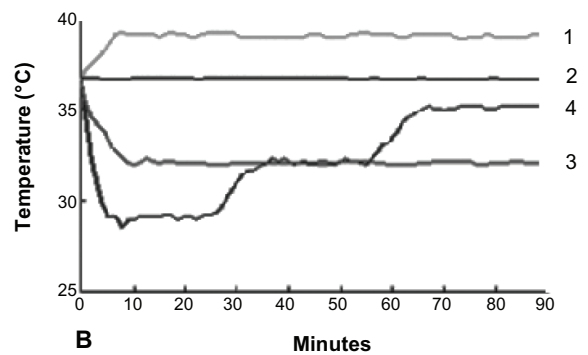

Figure 5 The manipulation of brain temperature. Different target temperatures: Left (A), $39^{\circ} \mathrm{C}(\mathrm{I}), 37^{\circ} \mathrm{C}(2), 35^{\circ} \mathrm{C}(3), 32^{\circ} \mathrm{C}(4)$, and $29^{\circ} \mathrm{C}(5)$; $R$ ight $(\mathbf{B}), 39^{\circ} \mathrm{C}(\mathrm{I}), 37^{\circ} \mathrm{C}(2), 32^{\circ} \mathrm{C}(3)$ were maintained for 90 minutes. Three-phase manipulation of brain temperature (4) from $29^{\circ} \mathrm{C}$ to $32^{\circ} \mathrm{C}$ and then to $35^{\circ} \mathrm{C}$ was achieved, showing the flexibility of the system. 
Table I MABP and HBR measurements before and after temperature manipulation

\begin{tabular}{llllll}
\hline & \multicolumn{2}{l}{ MABP $\mathbf{~ m m H g}$} & & \multicolumn{2}{l}{ HBR (beats/min) } \\
\cline { 2 - 3 } \cline { 6 - 6 } & Before & After & & Before & After \\
\hline Ratl $\left(39^{\circ} \mathrm{C}\right)$ & 76.0 & 80.0 & & 367 & 372 \\
Rat2 $\left(37^{\circ} \mathrm{C}\right)$ & 76.5 & 72.5 & & 388 & 375 \\
Rat3 $\left(35^{\circ} \mathrm{C}\right)$ & 70.0 & 70.0 & & 367 & 372 \\
Rat4 $\left(32^{\circ} \mathrm{C}\right)$ & 77.0 & 73.0 & & 370 & 340 \\
Rat5 $\left(29^{\circ} \mathrm{C}\right)$ & 74.8 & 71.5 & & 381 & 337 \\
\hline
\end{tabular}

Abbreviations: MABP, mean arterial blood pressure; HBR heart beat rate.

of the contralateral hemisphere) region without the ADC lesion in the ipsilateral hemisphere. A mirror of the core region in the contralateral hemisphere was chosen as the contra ROI. In contrast, an ROI encompassing both hemispheres, excluding the region at a proximity to the temperature probe, was outlined as sham ROI for rats in the sham group.

To derive the relationship between the change of CBF and change of temperature, a normalized $\mathrm{CBF}$ was derived, with the mean value of $\mathrm{CBF}$ in the contra $\mathrm{ROI}$ at normal temperature $\left(37^{\circ} \mathrm{C}\right)$ used as reference.

\section{Temperature difference between brain and temporal muscle}

Five normal rats $(\mathrm{n}=5 ; 300 \pm 25 \mathrm{~g})$ were utilized to study the relationship between the temperature in the temporal muscle and brain. The same procedures outlined above for selective cooling of the brain were used. An additional optical thermal probe was inserted $10 \mathrm{~mm}$ into the cleft between the skull and temporal muscle. The temperature of the brain and temporal muscle were recorded simultaneously for 90 minutes after the brain temperature was reduced to $32^{\circ} \mathrm{C}$.

\section{Experimental results}

\section{Selective brain temperature manipulation}

The results showed the MR compatible selective brain temperature manipulation device achieved the targeted

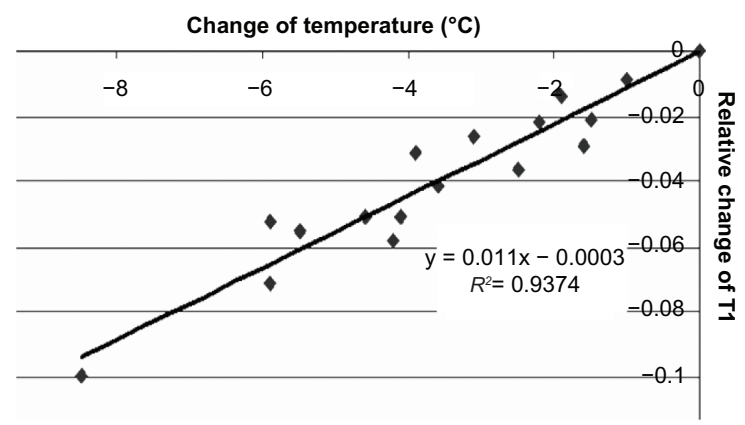

Figure 6 Change of relaxation TI versus change of temperature in the gray matter. brain temperature within 10 minutes and maintained it for 90 minutes. As demonstrated in Figure 5A, five different levels of targeted temperatures $\left(39^{\circ} \mathrm{C}, 37^{\circ} \mathrm{C}, 35^{\circ} \mathrm{C}, 32^{\circ} \mathrm{C}\right.$, and $\left.29^{\circ} \mathrm{C}\right)$ were achieved promptly $(<10$ minutes) and maintained for $90-120$ minutes with minimal variation $\left(<0.5^{\circ} \mathrm{C}\right)$. The rectal temperature remained in the normal range of $37.0^{\circ} \mathrm{C} \pm 0.5^{\circ} \mathrm{C}$ for all rats. Both MABP and HBR resided within their normal levels under all manipulation (Table 1). There was no significant difference found in MABP $(P=0.40)$ and $\operatorname{HBR}(P=0.19)$, before and after the manipulation, by two-tailed Student's $t$-test.

The three-phase brain temperature manipulation is shown in Figure 5B. First, the $29^{\circ} \mathrm{C}$ targeted temperature was achieved within 10 minutes and maintained for 20 minutes. It was then rewarmed to $32^{\circ} \mathrm{C}$ within 10 minutes and maintained for another 20 minutes, and finally rewarmed to $35^{\circ} \mathrm{C}$ and maintained for the final 20 minutes. The rectal temperature was kept within the range of $37.0^{\circ} \mathrm{C} \pm 0.5^{\circ} \mathrm{C}$ during the entire process of temperature manipulation.

\section{Correlation between $\mathrm{TI}$ and brain temperature}

Spin-lattice relaxation time $\mathrm{T} 1$ was linearly proportional to temperature when it was below $45^{\circ} \mathrm{C} .{ }^{54-56}$ Our results also demonstrated a similar result. A highly linear correlation $(y=0.011 x-0.0003, R 2=0.9374)$ was found between the change of $\mathrm{T} 1$ and the change of temperature (range: $29^{\circ} \mathrm{C}-$ $37^{\circ} \mathrm{C}$ ) in the gray matter of the brain, as shown in Figure 6.

\section{Relationship between CBF and temperature}

The relationship between $\mathrm{CBF}$ and brain temperature at different ischemic severity is shown in Figure 7. Cooling the

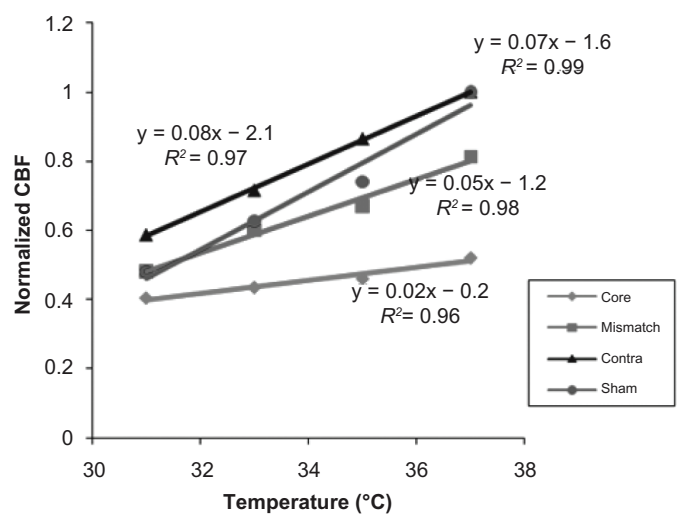

Figure 7 The change of $\mathrm{CBF}$ with temperature in different regions of brain in ischemic rats. The CBF in the sham group (circle) dropped most rapidly, followed by the contra region (triangles), mismatch region (squares), and the core region (diamonds). Abbreviation: $\mathrm{CBF}$, cerebral blood flow. 


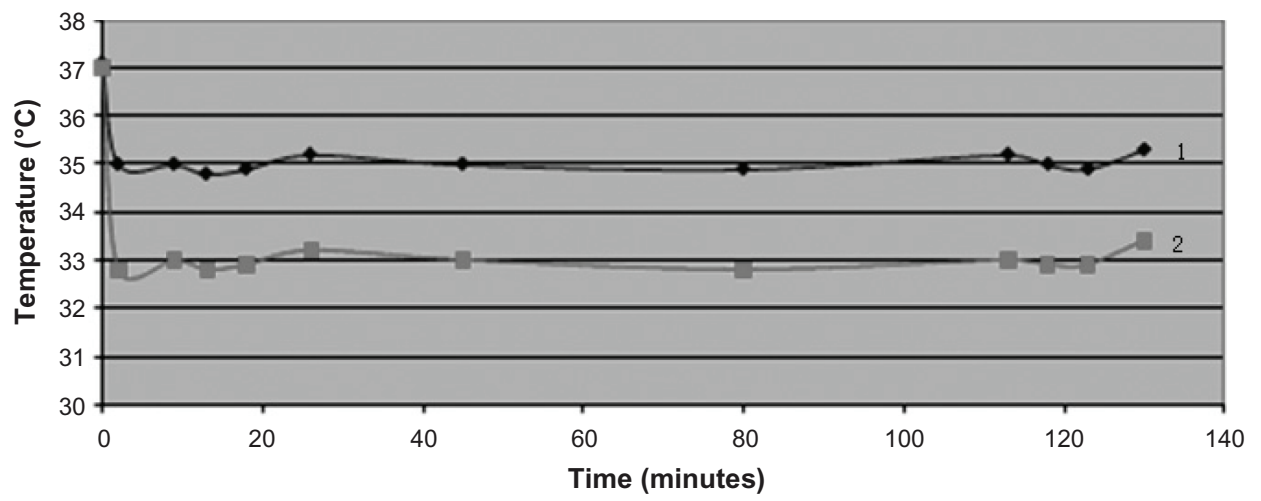

Figure 8 An example of the temperature difference between the brain (I) and temporal muscle (2) with selective brain surface cooling.

brain always resulted in decreases in $\mathrm{CBF}$, while the rate of decrease varied between the different regions. Highly linear relationships were observed between $\mathrm{CBF}$ and brain temperature independent of the brain perfusion status. However, the rate of $\mathrm{CBF}$ reduction in response to hypothermia differed among different ROIs. The sham group had the greatest slope $(y=0.08 x-2.1)$, followed by the contralateral region $(y=0.07 x-1.6)$, the mismatch region $(y=0.05 x-1.2)$, and the core lesion region $(y=0.02 x-0.2)$.

\section{Relation of temperature between brain and temple muscle}

As shown in Figure 8, a stable difference between the brain and temporal muscle temperature was found on each animal (only the result from one animal was shown) through the entire 90 minutes after the brain temperature reaches the target temperature of $32^{\circ} \mathrm{C}$. Although the magnitude of the temperature difference was different for each animal, from $2^{\circ} \mathrm{C}$ to $5^{\circ} \mathrm{C}$ respectively (not shown), the difference was stable throughout the whole cooling period for each animal.

\section{Conclusion and discussion}

We have designed a MR compatible selective brain temperature manipulation system that can manipulate the brain temperature of rats quickly and accurately while maintaining normal body temperature and physiology. The results showed that the targeted temperatures were reached within 10 minutes and were maintained for a long period of time ( $>90$ minutes), with minimal variation $\left(<0.5^{\circ} \mathrm{C}\right)$. The system was also very flexible and could produce the desired temperature pattern.

In our study, the BP seems low compared to other studies. The BP was measured from the femoral artery, with the sensor on the same level as the animal. One possible reason for the measured low BP is that there is a systemic bias of the device that we used. Because the device was connected to the femoral artery during the whole procedure of temperature manipulation for all the animals, the conclusion that there is no significant difference in BP during brain temperature manipulation should still be valid.

To ensure MR compatibility, two issues were addressed in the design. First, any metallic or ferromagnetic part was not allowed inside the scanner room due to safety considerations. Second, any radio frequencies generated by electronic components could affect the quality of the MR image. Thus, for our design, all the digital circuits were placed outside the scanner room. Optical fibers were utilized for the signal communication to eliminate the radio frequency interference. The MR compatibility of the system expands its application in preclinical studies.

The efficiency of cooling was closely related to the temperature of the cooling water and the rate of water flow. For this device, the temperature of the water was found to be the major factor affecting the cooling efficiency, while adjustment of the flow rate was utilized to enhance the initial cooling and as a fine adjustment once the target temperature was reached. For each targeted temperature, the temperature of the cooled water was manually preset $\left(4^{\circ} \mathrm{C}\right.$ for $29^{\circ} \mathrm{C}$ target temperature, $10^{\circ} \mathrm{C}$ for $32^{\circ} \mathrm{C}$, and $20^{\circ} \mathrm{C}$ for $35^{\circ} \mathrm{C}$ ). At the start of cooling, a high flow rate was used to expedite the cooling process. After the temperature was within $2^{\circ} \mathrm{C}$ of the target temperature, the rate of water flow was reduced slowly, until the target temperature was reached. The brain temperature could be maintained within $0.5^{\circ} \mathrm{C}$ of the targeted temperature by the adjustment of water flow during the stable period.

It has been suggested that brain metabolism is sensitive to temperature alterations; ${ }^{26-28}$ therefore in order to evaluate how temperature alters brain metabolism, an accurate measurement of brain temperature is important. In many studies, 
the temperature at the temporal muscle has been used as an indicator of brain temperature. However, it has been reported that the temperature in the temporal muscle does not accurately reflect the brain temperature..$^{57,58}$ In our study, surface cooling was used to produce hypothermia. A large temperature gradient was built across the brain from the warmer central structures to the cooler periphery (as big as from $10^{\circ} \mathrm{C}$ on the surface to $30^{\circ} \mathrm{C}$ inside the brain). The temperature at the temporal muscle was much lower than the brain, because it is closer to the surface cooling coil. In addition, under certain circumstances, direct measurement of the brain temperature with a temperature probe is not applicable due to its invasive nature, and its inability to provide a spatial temperature distribution. Thus, for many applications, a pixel-by-pixel noninvasive brain temperature map is preferred. Five noninvasive brain temperature mapping MR techniques have been proposed: the longitudinal relaxation time $\mathrm{T} 1,54,55$ the $\mathrm{ADC},{ }^{59}$ the proton resonance frequency of tissue water, ${ }^{60,61}$ proton spectroscopic imaging, ${ }^{62-64}$ and temperature-sensitive contrast agents. ${ }^{65}$ We chose the $\mathrm{T} 1$ based method for brain temperature mapping because the other four methods have drawbacks that make them unsuitable for an ischemic stroke study. These limitations include: (1) For the diffusion coefficient method, the ADC value can change within 10 minutes after ischemic occlusion, ${ }^{66}$ resulting in an inaccurate temperature measurement; (2) Proton resonance frequency of water can be changed when cerebral hemodynamics are altered; (3) The temperature sensitive contrast agents usually have a nonlinear response to temperature making their relationship hard to define; (4) The spatial resolution of proton spectroscopy is usually very poor and not suitable for temperature mapping. Alternatively, for T1 mapping methods, a highly linear relationship between the change of temperature and $\mathrm{T} 1$ has been reported, and there is no $\mathrm{T} 1$ change immediately after ischemic occlusion at magnetic fields $<3 \mathrm{~T}$.

In our design, a thermo-probe is always required as the real time feedback signal for the system. It has been reported that the temperature in the temporal muscle cannot accurately reflect the brain temperature. ${ }^{57}$ In our study, the temperature difference between the temporal muscle and brain ranged from $2^{\circ} \mathrm{C}$ to $5^{\circ} \mathrm{C}$ across different animals. There are two possible reasons for these variations. First, the temperature gradient under surface cooling makes the temperature measurement very sensitive to the position of the probe. Second, the fit of the cooling coil to the animal head could vary for different animals, resulting in variations in heat conductance. Nevertheless, although the temperature difference between the temporal muscle and brain varies from animal to animal, it remains stable over a long period of time for each individual animal. This stable relationship allows us to use the temporal muscle temperature as the feedback control signal to keep the brain temperature stable for the desired period of time. Since the $\mathrm{T} 1$ map could be used to derive the brain temperature after data acquisition, we could classify the animals into different groups during the later data analysis stage.

Hypothermic conditions induce the reduction of $\mathrm{CBF}$ in a normal brain. This finding was consistent with findings previously reported by Cheng et al ${ }^{67}$ and Laptook et al. ${ }^{68}$ They reported that a decrease of temperature of about $4^{\circ} \mathrm{C}$ (systemic cooling) resulted in a reduction of $40 \%$ of CBF. In our study, a comparable result was found, with a $40 \%$ reduction of $\mathrm{CBF}$ when the brain temperature dropped from $37^{\circ} \mathrm{C}$ to $33^{\circ} \mathrm{C}$. There are several physiological factors that may account for the observed reduction of $\mathrm{CBF}$, such as changes of $\mathrm{BP}$ or changes of arterial blood gases. In our study, there was no significant change of MABP before and after the cooling, and blood gas was also well controlled by mechanical ventilation. It is highly possible that the status of auto-regulation plays a critical role on how $\mathrm{CBF}$ will respond to brain temperature manipulation. If the auto-regulation is dysfunctional in the core area it may be only slightly impaired in the mismatched region, leading to different $\mathrm{CBF}$ characteristics in response to temperature manipulation. More studies are needed to further investigate whether or not brain metabolism under hypothermia also responds in a similar manner as that of CBF.

For active animals, the brain temperature is tightly related to body temperature, ${ }^{69,70}$ because of the fast exchange of heat between the brain and body through blood flow. When the surface cooling was used to reduce the brain temperature, the efficiency of cooling depends on multiple factors, including the temperature of the cooling water, the flow of the cooling water, local blood flow, the temperature of the perfused blood, the heat production of the brain, and the thermal conductivity of brain tissue and muscle. Zhu and Diao's ${ }^{71}$ simulation shows the cooling efficiency is largely dependent on the depth of tissue. For small animals, the small diameter of the brain and the large contact surface make it much easier to reduce the brain temperature. Therefore, for larger animals or humans where the diameter of the brain is larger, it would be much harder to regulate brain temperature. Although our device works well on small animals such as rats, its efficiency of cooling on larger animals or humans needs further investigation. In addition, besides the external cooling, the brain temperature is affected by several other factors. Kiyatkin et a $1^{69,72}$ have shown that anesthesia or stress will also have an effect on 
hypothermia. So careful experiment design in these cases is critical before application of SBC devices.

Some similar SBC devices have been developed and utilized clinically and preclinically, eg, cool cap studies, ${ }^{73,74}$ the ChillerPad ${ }^{(\mathrm{TM})}$ system (Seacoast Technologies Inc, Portsmouth, NH), ${ }^{48}$ intravascular infusion of cold solution, ${ }^{46}$ local metal coil cooling, ${ }^{47}$ and SBC from the pharyngeal surface. ${ }^{75}$ Compared to those methods, the device we designed in this study has the following advantages. First, it is an effective way to induce local hypothermia condition in small animals in preclinical studies. It is very fast $(<10 \mathrm{~min})$ with a wide temperature range (as low as $29^{\circ} \mathrm{C}$ ), accurate, and maintains temperature $\left(<0.5^{\circ} \mathrm{C}\right)$ in a controllable way. Second, it is MR compatible, which extends its application for MR imaging studies, while most other methods have no proven record on working under a MR environment. Third, the setting up of the device is simple and flexible, and doesn't need a stereotaxic holder or specially designed frame. This gives it the flexibility to be used in a variety of experimental conditions. Fourth, in our model, the method of deriving the temperature with T1 mapping has been validated, which not only makes the temperature measurement noninvasive, but also provides the spatial distribution of temperature. Fifth, with our system, a stable relationship of temperature between the temporal muscle and brain under hypothermia has been found, which could have potential applications in other studies needing temperature control.

This system has been proven to maintain brain hypothermia under anesthesia for as long as 90 minutes successfully. For studies needing longer durations, an improved design will be needed to allow the animal to wake up and move free in the cage. Improvements could possibly be done by using stretchable tubes and limiting the animal activity space, etc.

In conclusion, in our study, a selective brain temperature manipulation device has been designed and verified in a MR environment. This device has potential to be a valuable tool to further understand the mechanisms of local hypothermic and hyperthermic conditions in preclinical studies of the brain.

\section{Acknowledgments}

This study was supported by grants from the American Heart Association (AHA 0730321N) and National Institute of Health (NIH 5R01NS054079).

\section{Disclosure}

The authors report no conflicts of interest in this work.

\section{References}

1. Bernard SA, Gray TW, Buist MD, et al. Treatment of comatose survivors of out-of-hospital cardiac arrest with induced hypothermia. $N \mathrm{Engl}$ J Med. 2002;346(8):557-563.

2. Shankaran S, Laptook AR, Ehrenkranz RA, et al. Whole-body hypothermia for neonates with hypoxic-ischemic encephalopathy. N Engl J Med. 2005;353(15):1574-1584.

3. Reith J, Jorgensen HS, Pedersen PM, et al. Body temperature in acute stroke: relation to stroke severity, infarct size, mortality, and outcome. Lancet. 1996;347(8999):422-425.

4. Castillo J, Davalos A, Marrugat J, Noya M. Timing for fever-related brain damage in acute ischemic stroke. Stroke. 1998;29(12):2455-2460.

5. Takata T, Nabetani M, Okada Y. Effects of hypothermia on the neuronal activity, $[\mathrm{Ca} 2+] \mathrm{i}$ accumulation and ATP levels during oxygen and/or glucose deprivation in hippocampal slices of guinea pigs. Neurosci Lett. 1997;227(1):41-44.

6. Bacher A, Kwon JY, Zornow MH. Effects of temperature on cerebral tissue oxygen tension, carbon dioxide tension, and $\mathrm{pH}$ during transient global ischemia in rabbits. Anesthesiology. 1998;88(2):403-409.

7. Lanier WL. Cerebral metabolic rate and hypothermia: their relationship with ischemic neurologic injury. J Neurosurg Anesthesiol. 1995;7(3): 216-221.

8. Sakoh M, Gjedde A. Neuroprotection in hypothermia linked to redistribution of oxygen in brain. Am J Physiol Heart Circ Physiol. 2003; 285(1):H17-H25.

9. Rosomoff HL, Holaday DA. Cerebral blood flow and cerebral oxygen consumption during hypothermia. Am J Physiol. 1954;179(1): 85-88.

10. Maier CM, Sun GH, Cheng D, Yenari MA, Chan PH, Steinberg GK. Effects of mild hypothermia on superoxide anion production, superoxide dismutase expression, and activity following transient focal cerebral ischemia. Neurobiol Dis. 2002;11(1):28-42.

11. Kil HY, Zhang J, Piantadosi CA. Brain temperature alters hydroxyl radical production during cerebral ischemia/reperfusion in rats. $J$ Cereb Blood Flow Metab. 1996;16(1):100-106.

12. Globus MY, Alonso O, Dietrich WD, Busto R, Ginsberg MD. Glutamate release and free radical production following brain injury: effects of posttraumatic hypothermia. J Neurochem. 1995;65(4):1704-1711.

13. Lei B, Adachi N, Arai T. The effect of hypothermia on $\mathrm{H} 2 \mathrm{O} 2$ production during ischemia and reperfusion: a microdialysis study in the gerbil hippocampus. Neurosci Lett. 1997;222(2):91-94.

14. Wenisch C, Narzt E, Sessler DI, et al. Mild intraoperative hypothermia reduces production of reactive oxygen intermediates by polymorphonuclear leukocytes. Anesth Analg. 1996;82(4):810-816.

15. Winfree CJ, Baker CJ, Connolly ES Jr, Fiore AJ, Solomon RA. Mild hypothermia reduces penumbral glutamate levels in the rat permanent focal cerebral ischemia model. Neurosurgery. 1996;38(6): 1216-1222.

16. Takagi K, Ginsberg MD, Globus MY, Martinez E, Busto R. Effect of hyperthermia on glutamate release in ischemic penumbra after middle cerebral artery occlusion in rats. Am J Physiol. 1994;267(5 Pt 2): H1770-H1776.

17. Nakashima K, Todd MM. Effects of hypothermia on the rate of excitatory amino acid release after ischemic depolarization. Stroke. 1996; 27(5):913-918.

18. Maier CM, Ahern K, Cheng ML, Lee JE, Yenari MA, Steinberg GK. Optimal depth and duration of mild hypothermia in a focal model of transient cerebral ischemia: effects on neurologic outcome, infarct size, apoptosis, and inflammation. Stroke. 1998;29(10):2171-2180.

19. Xu L, Yenari MA, Steinberg GK, Giffard RG. Mild hypothermia reduces apoptosis of mouse neurons in vitro early in the cascade. J Cereb Blood Flow Metab. 2002;22(1):21-28.

20. Yenari MA, Iwayama S, Cheng D, et al. Mild hypothermia attenuates cytochrome c release but does not alter Bcl-2 expression or caspase activation after experimental stroke. J Cereb Blood Flow Metab. 2002; 22(1):29-38. 
21. Karibe H, Zarow GJ, Graham SH, Weinstein PR. Mild intraischemic hypothermia reduces postischemic hyperperfusion, delayed postischemic hypoperfusion, blood-brain barrier disruption, brain edema, and neuronal damage volume after temporary focal cerebral ischemia in rats. J Cereb Blood Flow Metab. 1994;14(4): 620-627.

22. Huang ZG, Xue D, Preston E, Karbalai H, Buchan AM. Biphasic opening of the blood-brain barrier following transient focal ischemia: effects of hypothermia. Can J Neurol Sci. 1999;26(4):298-304.

23. Kawai N, Kawanishi M, Okauchi M, Nagao S. Effects of hypothermia on thrombin-induced brain edema formation. Brain Res. 2001;895(1-2): 50-58.

24. Kollmar R, Schabitz WR, Heiland S, et al. Neuroprotective effect of delayed moderate hypothermia after focal cerebral ischemia: an MRI study. Stroke. 2002;33(7):1899-1904.

25. van der Worp HB, Sena ES, Donnan GA, Howells DW, Macleod MR. Hypothermia in animal models of acute ischaemic stroke: a systematic review and meta-analysis. Brain. 2007;130(Pt 12):3063-3074.

26. Busto R, Dietrich WD, Globus MY, Valdes I, Scheinberg P, Ginsberg MD. Small differences in intraischemic brain temperature critically determine the extent of ischemic neuronal injury. $J$ Cereb Blood Flow Metab. 1987;7(6):729-738.

27. Ginsberg MD, Busto R. Combating hyperthermia in acute stroke: a significant clinical concern. Stroke. 1998;29(2):529-534.

28. Ginsberg MD, Sternau LL, Globus MY, Dietrich WD, Busto R. Therapeutic modulation of brain temperature: relevance to ischemic brain injury. Cerebrovasc Brain Metab Rev. 1992;4(3):189-225.

29. Kawai N, Okauchi M, Morisaki K, Nagao S. Effects of delayed intraischemic and postischemic hypothermia on a focal model of transient cerebral ischemia in rats. Stroke. 2000;31(8):1982-1989; discussion 1989.

30. Zhang RL, Chopp M, Chen H, Garcia JH, Zhang ZG. Postischemic (1 hour) hypothermia significantly reduces ischemic cell damage in rats subjected to 2 hours of middle cerebral artery occlusion. Stroke. 1993;24(8):1235-1240.

31. Onesti ST, Baker CJ, Sun PP, Solomon RA. Transient hypothermia reduces focal ischemic brain injury in the rat. Neurosurgery. 1991;29(3): 369-373.

32. Baker CJ, Onesti ST, Barth KN, Prestigiacomo CJ, Solomon RA. Hypothermic protection following middle cerebral artery occlusion in the rat. Surg Neurol. 1991;36(3):175-180.

33. Kader A, Brisman MH, Maraire N, Huh JT, Solomon RA. The effect of mild hypothermia on permanent focal ischemia in the rat. Neurosurgery. 1992;31(6):1056-1060; discussion 1060-1051.

34. Baker CJ, Onesti ST, Solomon RA. Reduction by delayed hypothermia of cerebral infarction following middle cerebral artery occlusion in the rat: a time-course study. J Neurosurg. 1992;77(3):438-444.

35. Markarian GZ, Lee JH, Stein DJ, Hong SC. Mild hypothermia: therapeutic window after experimental cerebral ischemia. Neurosurgery. 1996;38(3):542-550; discussion 551.

36. Huh PW, Belayev L, Zhao W, Koch S, Busto R, Ginsberg MD. Comparative neuroprotective efficacy of prolonged moderate intraischemic and postischemic hypothermia in focal cerebral ischemia. J Neurosurg. 2000;92(1):91-99.

37. Colbourne F, Corbett D, Zhao Z, Yang J, Buchan AM. Prolonged but delayed postischemic hypothermia: a long-term outcome study in the rat middle cerebral artery occlusion model. J Cereb Blood Flow Metab. 2000;20(12):1702-1708

38. Corbett D, Hamilton M, Colbourne F. Persistent neuroprotection with prolonged postischemic hypothermia in adult rats subjected to transient middle cerebral artery occlusion. Exp Neurol. 2000;163(1): 200-206.

39. Maier CM, Sun GH, Kunis D, Yenari MA, Steinberg GK. Delayed induction and long-term effects of mild hypothermia in a focal model of transient cerebral ischemia: neurological outcome and infarct size. J Neurosurg. 2001;94(1):90-96.
40. Du C, Hu R, Csernansky CA, Hsu CY, Choi DW. Very delayed infarction after mild focal cerebral ischemia: a role for apoptosis? J Cereb Blood Flow Metab. 1996;16(2):195-201.

41. Schwab S, Schwarz S, Spranger M, Keller E, Bertram M, Hacke W. Moderate hypothermia in the treatment of patients with severe middle cerebral artery infarction. Stroke. 1998;29(12):2461-2466.

42. Schwab S, Georgiadis D, Berrouschot J, Schellinger PD, Graffagnino C, Mayer SA. Feasibility and safety of moderate hypothermia after massive hemispheric infarction. Stroke. 2001;32(9):2033-2035.

43. Krieger DW, De Georgia MA, Abou-Chebl A, et al. Cooling for acute ischemic brain damage (cool aid): an open pilot study of induced hypothermia in acute ischemic stroke. Stroke. 2001;32(8):1847-1854.

44. Georgiadis D, Schwarz S, Kollmar R, Schwab S. Endovascular cooling for moderate hypothermia in patients with acute stroke: first results of a novel approach. Stroke. 2001;32(11):2550-2553.

45. De Georgia MA, Krieger DW, Abou-Chebl A, et al. Cooling for Acute Ischemic Brain Damage (COOL AID): a feasibility trial of endovascular cooling. Neurology. 2004;63(2):312-317.

46. Takayama R, Uda R, Isono N, et al. Selective brain hypothermia suppresses noxious-evoked movement in canines. Anesth Analg. 2005; 100(5):1458-1462.

47. Clark DL, Colbourne F. A simple method to induce focal brain hypothermia in rats. J Cereb Blood Flow Metab. 2007;27(1):115-122.

48. Wagner KR, Zuccarello M. Local brain hypothermia for neuroprotection in stroke treatment and aneurysm repair. Neurol Res. 2005;27(3): 238-245.

49. Mayer SA, Kowalski RG, Presciutti M, et al. Clinical trial of a novel surface cooling system for fever control in neurocritical care patients. Crit Care Med. 2004;32(12):2508-2515.

50. Brix G, Schad LR, Deimling M, Lorenz WJ. Fast and precise T1 imaging using a TOMROP sequence. Magn Reson Imaging. 1990;8(4): $351-356$.

51. Longa EZ, Weinstein PR, Carlson S, Cummins R. Reversible middle cerebral artery occlusion without craniectomy in rats. Stroke. 1989; 20(1):84-91.

52. Williams DS, Detre JA, Leigh JS, Koretsky AP. Magnetic resonance imaging of perfusion using spin inversion of arterial water. Proc Natl Acad Sci U S A. 1992;89(1):212-216.

53. Alsop DC, Detre JA. Reduced transit-time sensitivity in noninvasive magnetic resonance imaging of human cerebral blood flow. $J$ Cereb Blood Flow Metab. 1996;16(6):1236-1249.

54. Parker DL, Smith V, Sheldon P, Crooks LE, Fussell L. Temperature distribution measurements in two-dimensional NMR imaging. Med Phys. 1983;10(3):321-325.

55. Dickinson RJ, Hall AS, Hind AJ, Young IR. Measurement of changes in tissue temperature using MR imaging. J Comput Assist Tomogr. 1986; 10(3):468-472.

56. Quesson B, de Zwart JA, Moonen CT. Magnetic resonance temperature imaging for guidance of thermotherapy. J Magn Reson Imaging. 2000; 12(4):525-533.

57. Jiang JY, Lyeth BG, Kapasi MZ, Jenkins LW, Povlishock JT. Moderate hypothermia reduces blood-brain barrier disruption following traumatic brain injury in the rat. Acta Neuropathologica. 1992;84(5):495-500.

58. Tang JS, Kiyatkin EA. Fluctuations in brain temperature induced by lipopolysaccharides: central and peripheral contributions. Oxid Med Cell Longev. 2010;3(5):332-341.

59. Le Bihan D, Delannoy J, Levin RL. Temperature mapping with MR imaging of molecular diffusion: application to hyperthermia. Radiology. 1989;171(3):853-857.

60. De Poorter J. Noninvasive MRI thermometry with the proton resonance frequency method: study of susceptibility effects. Magn Reson Med. 1995;34(3):359-367.

61. De Poorter J, De Wagter C, De Deene Y, Thomsen C, Stahlberg F, Achten E. Noninvasive MRI thermometry with the proton resonance frequency (PRF) method: in vivo results in human muscle. Magn Reson Med. 1995;33(1):74-81 
62. Kuroda K, Suzuki Y, Ishihara Y, Okamoto K. Temperature mapping using water proton chemical shift obtained with 3D-MRSI: feasibility in vivo. Magn Reson Med. 1996;35(1):20-29.

63. Kuroda K, Chung AH, Hynynen K, Jolesz FA. Calibration of water proton chemical shift with temperature for noninvasive temperature imaging during focused ultrasound surgery. J Magn Reson Imaging. 1998;8(1):175-181.

64. Kuroda K, Mulkern RV, Oshio K, et al. Temperature mapping using the water proton chemical shift: self-referenced method with echo-planar spectroscopic imaging. Magn Reson Med. 2000;44(1):167.

65. Salomir R, Palussiere J, Fossheim SL, et al. Local delivery of magnetic resonance (MR) contrast agent in kidney using thermosensitive liposomes and MR imaging-guided local hyperthermia: a feasibility study in vivo. J Magn Reson Imaging. 2005;22(4):534-540.

66. Kucharczyk J, Mintorovitch J, Asgari HS, Moseley M. Diffusion/ perfusion MR imaging of acute cerebral ischemia. Magn Reson Med. 1991;19(2):311-315.

67. Cheng G, Sun J, Wang L, Shao X, Zhou W. Effects of selective head cooling on cerebral blood flow and metabolism in newborn piglets after hypoxia-ischemia. Early Hum Develop. 2011;87(2):109-114.

68. Laptook AR, Shalak L, Corbett RJ. Differences in brain temperature and cerebral blood flow during selective head versus whole-body cooling. Pediatrics. 2001;108(5):1103-1110.
69. Kiyatkin EA, Brown PL. Brain and body temperature homeostasis during sodium pentobarbital anesthesia with and without body warming in rats. Physiol Behav. 2005;84(4):563-570.

70. Kiyatkin EA. Brain temperature homeostasis: physiological fluctuations and pathological shifts. Frontiers Biosci. 2010;15:73-92.

71. Zhu L, Diao C. Theoretical simulation of temperature distribution in the brain during mild hypothermia treatment for brain injury. Med Biol Eng Comput. 2001;39(6):681-687.

72. Kiyatkin EA, Wise RA. Striatal hyperthermia associated with arousal: intracranial thermorecordings in behaving rats. Brain Res. 2001; 918(1-2): 141-152.

73. Gluckman PD, Wyatt JS, Azzopardi D, et al. Selective head cooling with mild systemic hypothermia after neonatal encephalopathy: multicentre randomised trial. Lancet. 2005;365(9460):663-670.

74. Gunn AJ, Gluckman PD. Head cooling for neonatal encephalopathy: the state of the art. Clin Obstet Gynecol. 2007;50(3):636-651.

75. Trubel H, Herman P, Kampmann C, et al. A novel approach for selective brain cooling: implications for hypercapnia and seizure activity. Intensive Care Med. 2004;30(9):1829-1833.
Medical Devices: Evidence and Research

\section{Publish your work in this journal}

Medical Devices: Evidence and Research is an international, peerreviewed, open access journal that focuses on the evidence, technology, research, and expert opinion supporting the use and application of medical devices in the diagnosis, treatment and management of clinical conditions and physiological processes. The identification of novel

\section{Dovepress}

devices and optimal use of existing devices which will lead to improved clinical outcomes and more effective patient management and safety is a key feature. The manuscript management system is completely online and includes a quick and fair peer-review system. Visit http://www. dovepress.com/testimonials.php to read real quotes from authors. 